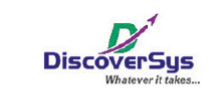

Published by DiscoverSys

\section{Determinants of caesarean section among women of child bearing age in Indonesia: Secondary data analysis of the 2017 Indonesia Demographic Health Survey}

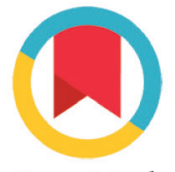

CrossMark

\author{
Desak Nyoman Purniati, ${ }^{1 *}$ Dewa Nyoman Wirawan, ${ }^{2}$ Luh Seri Ani ${ }^{2}$
}

\section{ABSTRACT}

Background and purpose: The caesarean section (CS) trend continues to increase throughout the world, including Indonesia. Indonesia is one of the countries where the proportion of CS exceeds the WHO recommendation. CS on medical indications can save the mother and baby, but if the $\mathrm{CS}$ is performed without any medical indication it will affect the welfare and health of both. This study was conducted to determine the factors associated with CS deliveries in women of childbearing age (WCA) in Indonesia.

Methods: This study is a secondary data analysis using the 2017 Indonesia Demographic and Health Survey (IDHS) data. The data analyzed in this study were $C S$ deliveries in the last 5 years and predictors variables which were collected via interviews. The number of samples in this analysis were 14,533 respondents from the total sample size of the 2017 IDHS as many as 50,730 female respondents aged 15-49 years. Data analysis was performed using multivariate logistic regression with backward method.

Results: The proportion of CS among women aged 15-49 years in Indonesia was 17.7\% (95\%Cl: 17.4-18\%). The risk factors for CS were age $>35$ years with $\mathrm{AOR}=2.35(95 \% \mathrm{Cl}: 1.61-3.44)$, primiparity with
$A O R=2.03(95 \% \mathrm{Cl}: 1.54-2.68)$, multiparity with $\mathrm{AOR}=1.53(95 \% \mathrm{Cl}$ : 1.18-1.99), low infant weight with $A 0 R=1.71$ (95\%Cl: 1.45-2.03), maternal high education level with $A 0 R=2.15(95 \% \mathrm{Cl}: 1.79-2.59)$, husband's middle education level with $A 0 R=1.41$ (95\%Cl: 1.23 1.62), urban areas of residence with $A O R=1.28(95 \% \mathrm{Cl}: 1.15-1.41)$, high family wealth index with $A O R=1.87$ (95\%Cl: 1.64-2.13), has a health insurance with $\mathrm{AOR}=1.54$ (95\% $\mathrm{Cl}: 1.41-1.70)$, delivered the baby at a private health facility with $A 0 R=1.18(95 \% \mathrm{Cl}: 1.07-$ 1.31), number of ANC visits $\geq 4$ times with $A 0 R=1.87$ ( $95 \% \mathrm{Cl}: 1.42-$ 2.32), and have been exposed to information media with $A 0 R=2.01$ (95\%Cl: 1.02-3.97).

Conclusion: The proportion of CS delivery in Indonesia remains relatively high. Education for mothers and families about the impact of unnecessary $C S$ delivery needs to be increased so that mothers and families are able to make appropriate and rational decisions. Interventions should be focused on mothers and husbands who are more educated, have higher socioeconomic status, live in urban areas and have chosen delivery in private health facilities.

Keywords: caesarean section, childbirth, determinants, Indonesia Demographic and Health Survey

Cite this Article: Purniati, D.N.P., Wirawan, D.N., Ani, L.S. 2020. Determinants of caesarean section among women of childbearing age in Indonesia: Secondary data analysis of the 2017 Indonesia Demographic Health Survey. Public Health and Preventive Medicine Archive 8(2): 113-119. D01: 10.15562/phpma.v8i2.305

${ }^{1}$ School of Midwifery, Faculty of Sports and Health Sciences, Ganesha Education University ${ }^{2}$ Department of Public Health and Preventive Medicine, Faculty of Medicine, Udayana University

*Correspondence to: Desak Nyoman Purniati ; School of Midwifery, Faculty of Sports and Health Sciences, Ganesha Education University purniatidsk@yahoo.com

\section{INTRODUCTION}

Globally, the trend of deliveries by caesarean section (CS) has increased over the last few decades. ${ }^{1}$ Data from 169 countries which covers 98.4\% of births worldwide, indicates that 29.7 million births occurred via CS in 2015, which was almost double the number of CS births in 2000. ${ }^{2}$ The World Health Organization (WHO) determines that births with CS are expected to be between 10$15 \%$, however more than $15 \%$ rate of CS is reported to have occurred in half of the world's countries, while around $40 \%$ countries have CS rates of $<10 \%$ and about $10 \%$ countries have CS rates between 10-15\%. ${ }^{3}$ Countries with CS rates below $10 \%$ are considered to not have access to childbirth standard facilities, while countries with CS $>15 \%$ are considered excessive. ${ }^{4}$

Medically indicated CS can prevent maternal and neonatal mortality and morbidity, however there is no evidence to suggest a benefit for both mother and baby in non-medically indicated CS deliveries. ${ }^{4}$ Delivery with CS affects health in subsequent pregnancies which will increase the risk of hysterectomy in recurrent CS. ${ }^{5}$ Urinary tract infections are increased in mothers undergoing CS delivery and the risk of the baby having respiratory distress is higher in CS births compared to vaginal delivery. ${ }^{6}$ CS can also increase the likelihood of

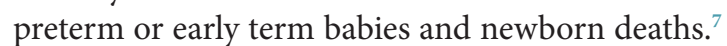
In some settings it was reported that maternal mortality can be $2-4$ times greater for SC than normal vaginal deliveries. ${ }^{8}$

A CS delivery can be justified for several medical indications such as fetal distress, prolonged labor, oligohydramnios, post-term pregnancy and other complications which occur during pregnancy or childbirth. ${ }^{9}$ WHO provides recommendations through the Robson classification for assessing, 
monitoring and comparing rates of CS in health care facilities which are internationally applicable. The WHO Robson classification categorizes women into ten groups based on obstetric characteristics (parity, history of CS, gestational age, onset of labor, fetal presentation and number of fetuses). This classification can be used as a tool to help reduce the rate of CS. ${ }^{4,10}$

CS deliveries in Indonesia are reported to have continued to increase, from $7 \%$ in 2007 , increasing to $12 \%$ in 2012 and $17 \%$ in $2017 .{ }^{11}$ Thus, the 2017 CS delivery rate in Indonesia has exceeded the WHO's recommendation. ${ }^{4} \mathrm{CS}$ is carried out with the aim of saving mothers and babies who cannot be born vaginally, but if it is done without any medical indication it will cause health problems for mothers and babies as well as financial burdens for the community, especially for low-income groups. ${ }^{12}$

The Indonesian government has implemented various key policies and programs in an effort to expand public access to maternal and newborn health services through the Birth Insurance Program (Program Jaminan Persalinan/Jampersal), National Health Insurance (Jaminan Kesehatan Nasionall $\mathrm{JKN}$ ) and the placement of midwives in villages. ${ }^{13}$ This policy helped reduce the maternal mortality rate from 359 per 100,000 live births in 2012 to 305 per 100,000 live births in $2015 .{ }^{14}$ At the same time, however, increased access to health services may have led to an increase in unwanted CS deliveries which may lead to the possible negative effects of CS deliveries without medical indication.

Previous studies on the factors associated with CS deliveries have been carried out in various countries including Indonesia, but the results remain inconsistent. A study on cesarean delivery in the East Mediterranean region found that age, education, parity and place of residence were associated with an increase in CS deliveries. ${ }^{15}$ Women aged $>35$ years are at increased risk of CS delivery because they belong to high risk age group for childbirth. ${ }^{15}$ Improved communication via social media along with scientific advances, social and cultural changes tend to lead to changes in attitudes towards CS births. ${ }^{16}$ CS deliveries in developed countries have increased along with the increase in community income and the improvement of health systems in these countries which is likely to be the cause of an increase in childbirth through CS. ${ }^{17}$

The 2017 Indonesian Demographic and Health Survey (IDHS) or Survei Demografi dan Kesehatan Indonesia (SDKI) provides data on CS deliveries and a number of variables which may be associated with CS. So far there has been no published research on the determinants of childbirth with CS using the 2017 IDHS data. This study aims to determine the factors associated with CS delivery using the 2017 IDHS secondary data.

\section{METHODS}

The study is a secondary data analysis of the 2017 IDHS results. The detailed study design has been described in the 2017 IDHS Report. ${ }^{11}$ The survey was conducted with a cross-sectional design which took place from 24 July to 30 September 2017 in 34 provinces in Indonesia. The data collated for this analysis were data on maternal and child health, fertility and family planning. The number of samples in the 2017 IDHS was 50,730 currently married women aged 15-49 years or women of child bearing age (WCA). Samples were selected in two stratified stages. The first stage is to select a number of census blocks in a systematic probability proportional to size (PPS) with the size of the number of households in the 2010 population census. The second stage is to choose households in each selected census block. Based on the entire sample size of the 2017 IDHS, which amounted to 50,730 currently married women aged 15-49 years, 14,533 mothers aged 1549 years, married and living together and who gave birth to children in the last 5 years were analyzed in this study.

This study refers to the Leone $\mathrm{T}$ et al. Framework who conducted a study on the factors affecting the increase in cesarean section rates in six developing countries using Demographic and Health Surveys (DHS) data. Leone $\mathrm{T}$ et al study analyzed all women who had given birth and at the birth of their last child in the 3 years preceding the survey. ${ }^{18}$ The data analyzed in this study were the mode of delivery of the youngest child, the age of the mother at birth, parity, complications during delivery, baby weight, mother's education, husband's education, mother's employment, husband's employment, area of residence, wealth index, health insurance ownership, number of ANC visits, place of delivery and media exposure.

In our analysis, the mode of delivery of the youngest child was categorized into "CS" and "vaginal", the maternal age was grouped into three groups, namely <20, 20-35 and $>35$ years. Parity is categorized into primiparity (1x), multiparity $(2-4 \mathrm{x})$ and grandemultipara $(>4 \mathrm{x})$. Complications during delivery were categorized into "yes" and "no". Baby weight was classified into "low $(<2500$ gram)", "normal (2500-4000 gram)" and "high (>4000 gram)". Mother's and father's education are grouped into "low (no education, incomplete primary and completed primary)", "middle (incomplete secondary and completed secondary)" and "high (higher education)". Mother's and father's employment were categorized into "employed" 
and "unemployed". The areas of residence are categorized into "rural" and "urban". This study uses a wealth index calculated and provided by DHS and is developed using principal component analysis

Table 1. Characteristics of respondents

\begin{tabular}{|c|c|c|}
\hline Characteristics & $\mathbf{n}$ & $\%$ \\
\hline \multicolumn{3}{|l|}{ Age (years) } \\
\hline$<20$ & 337 & 2.3 \\
\hline $20-35$ & 10,503 & 72.3 \\
\hline$>35$ & 3,693 & 25.4 \\
\hline \multicolumn{3}{|l|}{ Parity } \\
\hline Primiparity & 4,775 & 32.9 \\
\hline Multiparity & 8,977 & 61.8 \\
\hline Grandemultipara & 780 & 5.3 \\
\hline \multicolumn{3}{|c|}{ Birth complications ${ }^{*}$} \\
\hline Yes & 10,008 & 68.9 \\
\hline No & 4,521 & 31.1 \\
\hline \multicolumn{3}{|l|}{ Infant birth weight* } \\
\hline Low & 926 & 6.7 \\
\hline Normal & 12,475 & 89.9 \\
\hline High & 475 & 3.4 \\
\hline \multicolumn{3}{|l|}{ Mother's education } \\
\hline Low & 3,908 & 26.9 \\
\hline Middle & 8,463 & 58.2 \\
\hline High & 2,161 & 14.9 \\
\hline \multicolumn{3}{|l|}{ Father's education ${ }^{*}$} \\
\hline Low & 4,172 & 28.8 \\
\hline Middle & 4,808 & 58.0 \\
\hline High & 1,910 & 13.2 \\
\hline \multicolumn{3}{|c|}{ Mother's employment } \\
\hline Employed & 7,417 & 51.0 \\
\hline Unemployed & 7,115 & 49.0 \\
\hline \multicolumn{3}{|c|}{ Father's employment ${ }^{*}$} \\
\hline Employed & 14,438 & 99.4 \\
\hline Unemployed & 87 & 0.6 \\
\hline \multicolumn{3}{|l|}{ Residence } \\
\hline Rural & 7,490 & 51.5 \\
\hline Urban & 7,043 & 48.5 \\
\hline \multicolumn{3}{|l|}{ Family wealth index } \\
\hline Underprivileged & 5,768 & 39.7 \\
\hline Middle income & 2,996 & 20.6 \\
\hline Wealthy & 5,769 & 39.7 \\
\hline \multicolumn{3}{|l|}{ Health insurance } \\
\hline Yes & 8,556 & 58.9 \\
\hline No & 5,977 & 41.1 \\
\hline \multicolumn{3}{|l|}{ ANC visits ${ }^{*}$} \\
\hline$<4$ times & 1,241 & 8.5 \\
\hline$\geq 4$ times & 13,286 & 91.5 \\
\hline \multicolumn{3}{|l|}{ Delivery place } \\
\hline Public & 7,333 & 50.5 \\
\hline Private & 7,199 & 49.5 \\
\hline \multicolumn{3}{|l|}{ Media exposure } \\
\hline Yes & 14,268 & 98.5 \\
\hline No & 219 & 1.5 \\
\hline
\end{tabular}

* The number is smaller than 14,533 because there are missing data based on household ownership of several selected assets. The family wealth index is classified into "underprivileged", "middle income" and "wealthy". Health insurance ownership is categorized into "yes" and "no". The number of ANC visits was grouped into " $<4$ times" and " $\geq 4$ times". The women in this study were those who gave birth in health services so that the place of delivery was categorized as "public" and "private". Access to information via mass media is important to increase knowledge and concern for the environment and can influence attitudes and people's behavior so in this study media exposure is categorized into "exposed" and "never exposed".

Univariate analysis was conducted to determine the frequency distribution of each variable. Bivariate analysis was performed using the chisquare statistical test to determine the different proportions of SC by the independent variables. Multivariate analysis was performed using binary logistic regression with the backward method to obtain the adjusted odds ratio (AOR) of each independent variable. The analysis of this research has been weighted on the sample so that the sample data can represent the entire population. The missing data on each variable does not exceed 50\% so all of the variable is included in the analysis.

Primary data collection has received ethical approval from DHS and the Ministry of Health. This secondary analysis has obtained an ethical clearance from the Ethics Committee of the Faculty of Medicine, Udayana University/Sanglah General Hospital with number: 2020.02.1.0235 on April 6, 2020.

\section{RESULTS}

Of the 14,533 WCA included in the analysis, 2,575 (17.7\%) with 95\%CI: $17.4-18.0 \%$ experienced CS deliveries for the last child in the 5 years prior to the interview in the 2017 IDHS. The majority of the women were aged $20-35$ years (72.3\%), having 2-4 children/multiparity (61.8\%), experiencing birth complications (68.9\%) and having a baby with a normal birth weight (89.9\%). Meanwhile, more than half $(58.2 \%)$ of the mothers have a middle education level and similarly, $58.0 \%$ of the husbands have a middle education level, almost all (99.4\%) of the husbands were employed while half of the WCA (51\%) were employed. Almost all of the women (91.5\%) have the number of ANC visits $\geq 4$ times. More than half (58.9\%) owned health insurance and the majority (98.5\%) had been exposed to the media. The proportion of WCA who live in rural (51.5\%) and urban area (48.5\%) were almost equal and similar for the proportion of utilization of public delivery center $(50.5 \%)$ versus private 
services (49.5\%). Based on the family wealth index, it is found that the proportion of underprivileged and wealthy groups were equal at $39.7 \%$ (Table 1 ).

In Table 2, the proportion of CS deliveries is presented based on several independent variables

Table 2. The difference in the type of delivery of the last child in the 5 years preceding the survey based on several variables for WCA in Indonesia

\begin{tabular}{|c|c|c|c|c|c|}
\hline \multirow{3}{*}{ Variable } & \multicolumn{4}{|c|}{ Birth methods } & \multirow{3}{*}{$\mathbf{p}$} \\
\hline & \multicolumn{2}{|c|}{ CS } & \multicolumn{2}{|c|}{ Vaginal } & \\
\hline & $\mathbf{n}$ & $\%$ & $\mathbf{n}$ & $\%$ & \\
\hline Age (years) & & & & & $\mathrm{p}<0.001$ \\
\hline$<20$ & 36 & 10.7 & 301 & 89.3 & \\
\hline $20-35$ & 1,696 & 16.1 & 8,807 & 83.9 & \\
\hline$>35$ & 843 & 22.8 & 2,850 & 77.2 & \\
\hline Parity & & & & & $\mathrm{p}<0.001$ \\
\hline Primiparity & 933 & 19.5 & 3,842 & 80.5 & \\
\hline Multiparity & 1,561 & 17.4 & 7,416 & 82.6 & \\
\hline Grandemultipara & 80 & 10.3 & 700 & 89.7 & \\
\hline Birth complications & & & & & $\mathrm{p}<0.001$ \\
\hline Yes & 1,954 & 19.5 & 8,054 & 80.5 & \\
\hline No & 619 & 13.7 & 3,903 & 86.3 & \\
\hline Infant birth weight & & & & & $\mathrm{p}<0.001$ \\
\hline Low & 221 & 23.8 & 706 & 76.2 & \\
\hline Normal & 2,246 & 18.0 & 10,229 & 82.0 & \\
\hline High & 96 & 20.2 & 379 & 79.8 & \\
\hline Mother's education & & & & & $\mathrm{p}<0.001$ \\
\hline Low & 359 & 9.2 & 3,549 & 90.8 & \\
\hline Middle & 1,485 & 17.5 & 6,978 & 82.5 & \\
\hline High & 730 & 33.8 & 1,431 & 66.2 & \\
\hline Father's education & & & & & $\mathrm{p}<0.001$ \\
\hline Low & 381 & 9.1 & 3,792 & 90.9 & \\
\hline Middle & 1,587 & 18.9 & 6,821 & 81.1 & \\
\hline High & 596 & 31.2 & 1,314 & 68.8 & \\
\hline Mother's employment & & & & & $\mathrm{p}<0.001$ \\
\hline Employed & 1,417 & 19.1 & 6,000 & 80.9 & \\
\hline Unemployed & 1,158 & 16.3 & 5,957 & 83.7 & \\
\hline Father's employment & & & & & 0.311 \\
\hline Employed & 2,553 & 17.7 & 11,885 & 82.3 & \\
\hline Unemployed & 19 & 21.8 & 68 & 78.2 & \\
\hline Area of residence & & & & & $\mathrm{p}<0.001$ \\
\hline Rural & 923 & 12.3 & 6,566 & 87.7 & \\
\hline Urban & 1,651 & 23.4 & 5,392 & 76.6 & \\
\hline Family wealth & & & & & $\mathrm{p}<0.001$ \\
\hline Underprivileged & 527 & 9.1 & 5,241 & 90.9 & \\
\hline Middle income & 470 & 15.7 & 2,526 & 84.3 & \\
\hline Wealthy & 1,578 & 27.4 & 4,191 & 72.6 & \\
\hline Health insurance & & & & & $\mathrm{p}<0.001$ \\
\hline Yes & 1,821 & 21.3 & 6,735 & 78.7 & \\
\hline No & 753 & 12.6 & 5,224 & 87.4 & \\
\hline ANC visits & & & & & $\mathrm{p}<0.001$ \\
\hline$<4$ times & 79 & 6.4 & 1,162 & 93.6 & \\
\hline$\geq 4$ times & 2,493 & 18.8 & 10,794 & 81.2 & \\
\hline Delivery place & & & & & $\mathrm{p}<0.001$ \\
\hline Public & 986 & 13.4 & 6,348 & 86.6 & \\
\hline Private & 1,589 & 22.1 & 5,610 & 77.9 & \\
\hline Media exposure & & & & & $\mathrm{p}<0.001$ \\
\hline Yes & 2,558 & 17.9 & 11,711 & 82.1 & \\
\hline No & 13 & 5.9 & 206 & 94.1 & \\
\hline
\end{tabular}

and a statistical test performed using the chisquare test. There was a significant difference in the proportions $(\mathrm{p} \leq 0.05)$ based on maternal age, parity, delivery complications, infant's weight, mother's education, husband's education, maternal employment, area of residence, family wealth index, health insurance ownership, number of ANC visits, place of delivery and media exposure.

The proportion of CS was increased with the increase of age group. It was the highest among primipara mothers and those with birth complication. CS were more prevalent among both low (23.8\%) and high infant weight (20.2\%) compared to normal weight (18.0\%). Proportion of CS increased with the increased level of education among both mothers and the fathers, and slightly higher among those who are employed, both for the mothers and fathers. CS was also higher among women who reside in the urban area $(23.4 \%)$, had higher income status, gave birth at private services (22.1\%), owned a health insurance (21.3\%), exposed to media (17.9\%) and those who had more than 4 ANC visits (18.8\%).

In Table 3, the results of multivariate analysis with binary logistic regression using backward method are presented. It can be seen that the variables associated with CS delivery were age $>35$ years with $\mathrm{AOR}=2.35$ (95\%CI: 1.61-3.44), primiparity $(1 \mathrm{x})$ with $\mathrm{AOR}=2.03$ (95\%CI: 1.54 2.68), multiparity $(2-4 \mathrm{x})$ with $\mathrm{AOR}=1.53$ (95\%CI: 1.18-1.99), low infant weight $(<2500$ gr) with AOR=1.71 (95\%CI: 1.45-2.03), overweight infants (>4000 gr) with $\mathrm{AOR}=1.37$ (95\%CI: $1.10-1.75)$, mother's middle education level with $\mathrm{AOR}=1.34$ (95\%CI: 1.16-1.54), high maternal education with $\mathrm{AOR}=2.15$ (95\%CI: 1.79-2.59), husband's middle education level with $\mathrm{AOR}=1.41 \quad(95 \% \mathrm{CI}$ : 1.231.62), high paternal education with $\mathrm{AOR}=1.40$ (95\%CI: 1.16-1.70), urban areas of residence with $\mathrm{AOR}=1.28$ (95\%CI: 1.15-1.41), wealthy families with $\mathrm{AOR}=1.87$ (95\%CI: 1.64-2.13), middle income family with $\mathrm{AOR}=1.30$ (95\%CI: $1.13-1.51)$, has a health insurance with AOR $=1.54$ (95\%CI: 1.411.70 ), delivery in a private health facility with $\mathrm{AOR}=1.18 \quad$ (95\%CI: 1.07-1.31), $\geq 4$ times ANC visits with $\mathrm{AOR}=1.87$ (95\%CI: $1.42-2.32)$ and being exposed to media with AOR=2.01 (95\%CI: $1.02-$ 3.97).

\section{DISCUSSION}

The proportion of CS births in Indonesia in this study was $17.7 \%$. This figure is higher than the 2017 IDHS report, which was $17 \%$. This is because the sample analyzed was only women who gave birth in the last 5 years before the survey, at the last birth, women who were married and lived together, so the 
Table 3. AOR of CS delivery based on several predictor variables

\begin{tabular}{|c|c|c|c|}
\hline Variable & AOR & $95 \% \mathrm{Cl}$ & $\mathbf{p}$ \\
\hline \multicolumn{4}{|l|}{ Age (years) } \\
\hline$<20$ & Ref & & \\
\hline $20-35$ & 1.243 & $0.862-1.792$ & 0.243 \\
\hline$>35$ & 2.351 & $1.608-3.437$ & $\mathrm{p}<0.001$ \\
\hline \multicolumn{4}{|l|}{ Parity } \\
\hline Grandemultipara & Ref & & \\
\hline Multiparity & 1.527 & $1.176-1.983$ & 0.001 \\
\hline Primiparity & 2.031 & $1.539-2.679$ & $\mathrm{p}<0.001$ \\
\hline \multicolumn{4}{|l|}{ Infant birth weight } \\
\hline Normal & Ref & & \\
\hline Low & 1.713 & $1.448-2.025$ & $\mathrm{p}<0.001$ \\
\hline High & 1.374 & $1.079-1.751$ & 0.010 \\
\hline \multicolumn{4}{|l|}{ Mother's education } \\
\hline Low & Ref & & \\
\hline Middle & 1.338 & $1.161-1.541$ & $\mathrm{p}<0.001$ \\
\hline High & 2.152 & $1.789-2.589$ & $\mathrm{p}<0.001$ \\
\hline \multicolumn{4}{|l|}{ Father's education } \\
\hline Low & Ref & & \\
\hline Middle & 1.407 & $1.227-1.615$ & $\mathrm{p}<0.001$ \\
\hline High & 1.403 & $1.160-1.698$ & $\mathrm{p}<0.001$ \\
\hline \multicolumn{4}{|l|}{ Area of residence } \\
\hline Rural & Ref & & \\
\hline Urban & 1.276 & $1.153-1.412$ & $\mathrm{p}<0.001$ \\
\hline \multicolumn{4}{|l|}{ Family wealth index } \\
\hline Underprivileged & Ref & & \\
\hline Middle income & 1.300 & $1.128-1.498$ & $\mathrm{p}<0.001$ \\
\hline Wealthy & 1.872 & $1.643-2.133$ & $\mathrm{p}<0.001$ \\
\hline \multicolumn{4}{|l|}{ Health insurance } \\
\hline No & Ref & & \\
\hline Yes & 1.541 & $1.396-1.701$ & $\mathrm{p}<0.001$ \\
\hline \multicolumn{4}{|l|}{ Delivery place } \\
\hline Public & Ref & & \\
\hline Private & 1.176 & $1.067-1.297$ & $\mathrm{p}<0.001$ \\
\hline \multicolumn{4}{|l|}{ ANC visits } \\
\hline$<4$ times & Ref & & \\
\hline$\geq 4$ times & 1.871 & $1.423-2.321$ & $\mathrm{p}<0.001$ \\
\hline \multicolumn{4}{|l|}{ Media exposure } \\
\hline No & Ref & & \\
\hline Yes & 2.013 & $1.021-3.969$ & 0.043 \\
\hline
\end{tabular}

denominator used was smaller than the 2017 IDHS analysis.

The results of the multivariate analysis indicate that the higher education level of mothers and fathers, urban living, higher wealth index, place of delivery in private hospitals and ownership of insurance significantly increase the proportion of CS delivery. In the bivariate analysis these factors were also found to be associated with access to health services. Mothers and husbands with higher education, live in urban areas, higher wealth index, place of delivery in private hospitals and has a health insurance may have easier access to CS delivery services and there is a possibility that CS deliveries were performed with non-medical indications. The results of a study in Jakarta reported that reasons for fear of pain, protecting the baby, determining the date of birth, cosmetic reasons and early delivery can drive an increase in the demand for CS. ${ }^{19}$ The results of studies in Rize Turki ${ }^{20}$ and in
Bangladesh ${ }^{12}$ also show that the rate of CS delivery increases with increasing education levels and wealth index and is influenced by the place of residence. Research in Mexiko ${ }^{21}$ and Chile ${ }^{22}$ showed that women with higher economic status prefer to give birth in private hospitals. Childbirth with nonmedical indications will have a negative impact on health services in Indonesia because Indonesia as a developing country has limited resources so that an increase in CS deliveries without medical indication will cause inefficiency in funding, infrastructure and human resources.

Health insurance participants in Indonesia consist of recipients of government assistance (penerima bantuan iuran/PBI) and non PBI or independent participants. Women who have health insurance and become PBI participants are reported to be $53 \%$ and only $3 \%$ have insurance managed by the private sector, so that the cost of childbirth for CS without medical indication that must be paid by the government is feared to cause inefficiency and increase the burden on the state budget because it is not well-targeted. Research in Switzerland shows that CS is higher among women who have health insurance and increases the chances of having a CS delivery. ${ }^{23}$ Research in Chile shows that CS deliveries in private hospitals experience a rapid increase with insurance ownership. ${ }^{22}$

This inefficiency will have an impact on the limited health services, especially for mothers with low socioeconomic conditions and those who live in rural areas where they are in dire need of more adequate health services, including delivery of CS. In addition, the low ownership of health insurance for women in rural areas, which is only $47 \%,{ }^{11}$ will make it more difficult to access services to perform the required CS delivery.

Besides being influenced by the level of education of mothers and fathers, higher wealth index, living in urban areas, giving birth in private hospitals and having health insurance, mother's age is also related to the birth of CS. Maternal age $>35$ years was most strongly associated with CS deliveries, wherein this group experienced CS deliveries 2.3 times higher than $<20$ years and $20-35$ years. This is probably because at the age of $>35$ years, complications are often found during pregnancy and during childbirth, so that delivery with CS should be done. Birth complication variables in this study did not have a significant relationship with caesarean section, possibly because complications have not occurred and the mother has decided to do a caesarean section delivery or it correlates to other independent variables. In addition, it may also be due to the inability or fear of the mother to carry out a normal delivery because her physical strength 
starts to decrease so that the mother takes the decision to deliver via CS. Research in Brazil shows that pregnant women $>35$ years of age experience fear, feel their physical strength decreased and feel unsure about having a normal delivery so the mothers chose a CS delivery. ${ }^{24}$ Another study conducted in Denmark shows a strong and consistent relationship between maternal age $>35$ years with CS delivery. ${ }^{25}$ Mothers in the 20-35 year age group have a lower risk of undergoing a CS delivery. This is likely that age of 20-35 years is the ideal age range for pregnancy and childbirth so that there is a smaller risk of experiencing complications that lead to CS delivery. ${ }^{26}$

Information from mass media about CS delivery can have an impact on decision-making in delivery that can increase the proportion of CS. ${ }^{27}$ The results of the multivariate analysis in our study indicate that media exposure have a significant relationship with CS delivery. The results of a study in Bangladesh showed that more CS births were carried out by mothers who had been exposed to media at least once a week..$^{12}$ This feeling of maternal concern is probably what drives mothers to frequently perform antenatal care.

In our study it was also found that the number of ANC visits was significantly associated with CS deliveries. This is probably because this group of women was asked to carry out ANC more frequently by health workers because of the possibility of abnormal conditions and the risk of experiencing complications during delivery. Being wealthy and having a higher education level may be associated with increased ANC visits. A Brazilian study also reported that the frequency of ANC visits was significantly associated with CS delivery. ${ }^{28}$

In our study, parity was also found to have a significant association with CS delivery. Mothers with primiparity were found to have a higher risk of having a CS delivery compared to other parities. Research in Bangladesh also showed that CS deliveries were highest at first births and that more than $16 \%$ of cesarean deliveries were requested by patients due to fear of pain. ${ }^{12}$ The results of another study in Turkey indicated that CS at first delivery were consistently increasing as influenced by with the desire to determine the day of birth. ${ }^{29}$ The desire to determine the day of birth and excessive worry may lead to an earlier labor through surgery and thus have an impact on the baby's weight at birth. In our study it was found that birth weight was significantly associated with CS delivery. This is probably because premature birth causes lower birth weight, especially in mothers who have anemia, hypertension and placenta previa, which are some of the factors that cause preterm birth, so that CS delivery is an option to save both mother and infant..$^{30}$

The limitation in this study is that the data used is secondary data, so that not all of the theoretically related variables with CS can be explored. In addition, this is a cross-sectional study that cannot show a causal relationship so that other studies are needed, such as prospective cohort studies and qualitative studies to obtain a more explicit explanation for the high proportion of caesarean section delivery.

\section{CONCLUSION}

The proportion of CS deliveries among WCA at the birth of the last child in the 5 years prior to IDHS in Indonesia was $17.7 \%$ and was higher than the WHO benchmark of $10-15 \%$. Maternal age of $>35$ years is the most strongly associated factor with CS delivery in Indonesia. Other factors are the mother's age, parity, birth weight, mother's education, husband's education, area of residence, family wealth index, health insurance ownership, number of ANC visits, place of delivery and media exposure. More intensive education from basic health services about rational CS delivery, especially the good age range for pregnancy, needs to be increased to reduce cesarean delivery without medical indication. In addition, qualitative research also needs to be carried out to explore more in-depth information about the reasons for conducting CS delivery.

\section{ACKNOWLEDGEMENTS}

Authors thank the National Population and Family Planning Agency for the data access provided to enable data analysis for the 2017 IDHS.

\section{AUTHOR CONTRIBUTION}

DNP designed and conceived the study, analysed the data, wrote the first draft of the manuscript and edited the manuscript. DNW and LSA were involved in the design and conception of the study, provided feedback and edited the manuscript.

\section{CONFLICT OF INTEREST STATEMENT:}

\section{None declared}

\section{REFERENCES}

1. World Health Organization. WHO recommendations: Non-clinical interventions to reduce unnecessary caesarean sections. Geneva: World Health Organization; 2018.

2. Boerma T, Ronsmans C, Melesse DY, Barros AJD, Barros FC, Juan L, et al. Global epidemiology of use of and disparities in caesarean sections. The Lancet. 2018;392:1341-1348.

3. Gibbons L, Belizán JM, Lauer JA, Betrán AP, Merialdi M, Althabe F. The global numbers and costs of additionally 
needed and unnecessary caesarean sections performed per year: Overuse as a barrier to universal coverage. World Health Report. 2010; 30.

4. World Health Organization. WHO statement on caesarean section rates. Geneva: World Health Organization; 2015.

5. Mascarello KC, Horta BL, Silveira MF. Maternal Complications and Cesarean Section Without Indication : Systematic Review and Meta-Analysis. Rev Saude Publica. 2017; 51:105

6. Lindgren $\mathrm{H}$, Hildingsson I. Maternal and infant outcome after caesarean section without recorded medical indication: findings from a Swedish case-control study. BJOG. 2013;120(4):479-486.

7. Kramer MS, Platt RW. The contribution of mild and moderate preterm birth to infant mortality. JAMA. 2000;284(7):843-849.

8. Wagner M. Choosing caesarean section. Lancet. 2000;356:1677-1680.

9. Neilson JP, Lavender T, Quenby S, Wray S. Obstructed labour. Br Med Bull. 2003;67:191-204.

10. Betrán AP, Ye J, Moller A, Zhang J, Gülmezoglu AM. The increasing trend in caesarean section rates: Global, regional and national estimates: 1990-2014. PLoS One. 2016;11(2):1-12.

11. National Demographic and Family Planning Agency. Survei Demografi dan Kesehatan Indonesia tahun 2017 [The 2017 Indonesia Demographic and Health Survey]. National Demographic and Family Planning Agency. Jakarta; 2017.

12. Rahman MM, Haider MR, Rahman AE, Ahmed S, Khan MM. Determinants of caesarean section in Bangladesh: Cross-sectional analysis of Bangladesh Demographic and Health Survey 2014 data. PLoS One. 2018;13(9):1-14.

13. Teplitskaya L, Dutta A. Apakah Skema Jaminan Kesehatan Nasional Indonesia meningkatkan akses ke layanan kesehatan ibu dan bayi baru lahir? [Does The Indonesia National Health Insurance Scheme increases access to mother and infant health services?]. Health Policy Plus. Washington DC; 2018.

14. The Ministry of Health of The Republic of Indonesia. Profil Kesehatan Indonesia Tahun 2017 [The 2017 Indonesia Health Profile]. The Ministry of Health of The Republic of Indonesia. Jakarta; 2018.

15. Mahaini R, Gholbzouri K, Jadoon B. Determinants of over and underuse of caesarean births in the Eastern Mediterranean Region: an updated review. East Mediterr Health J. 2019;1-18.

16. Rafiei M, Saei M, Naz G, Akbari M, Kiani F, Sayehmiri F, et al. Prevalence, causes, and complications of cesarean delivery in Iran: A systematic review and meta-analysis. Int J Reprod Biomed. 2018;16(4):221-234.

17. Lauer JA, Betrán AP, Merialdi M, Wojdyla D. Determinants of caesarean section rates in developed countries: supply, demand and opportunities for control. World Health Report. 2010; 29.
18. Leone T, Padmadas SS, Matthews Z. Community factors affecting rising caesarean section rates in developing countries: An analysis of six countries. Soc Sci Med. 2008;67(8):1236-1246.

19. Meiyetriani E, Utomo B, Budi B, Santoso I, Salmah S. Peran Dokter Ahli Kebidanan dan Kandungan [The roles of the obstetricians and gynecologists). Kesmas. 2012;7(1):37-43.

20. Ardic C. Role of mother education level in delivery method preference. Family Practice and Palliative Care. 2018;3(1):28-32.

21. Vega ES, Marta U, Fernando A, Begines L, Yazmin I, Christian HR. The Epidemic of the cesarean section in private hospital in Puebla, Mexico. Obstetrics \& Gynecology International Journal. 2015;2(6):184-187.

22. Borrescio-higa F, Valdés N. Publicly insured caesarean sections in private hospitals: a repeated cross- sectional analysis in Chile. BMJ Open. 2019;9(4):1-7.

23. Hoxha I, Syrogiannouli L, Braha M, Goodman DC, Costa BR, Jüni P. Caesarean sections and private insurance: Systematic review and meta-analysis. BMJ Open. 2017;7(8):1-10.

24. Aldrighi JD, Wall ML, Souza SRRK. Experience of pregnant women at an advanced age. Rev Gaucha Enferm. 2018;39:1-9.

25. Rydahl E, Declercq E, Juhl M, Maimburg RD. Cesarean section on a rise-does advanced maternal age explain the increase? A population register-based study. PLoS One. 2019;14(1):1-16.

26. Janoudi G, Kelly S, Yasseen A, Hamam H, Moretti F, Walker M. Factors associated with increased rates of caesarean section in women of advanced maternal age. $J$ Obstet Gynaecol Canada. 2015;37(6):517-526.

27. Suwanrath C, Chunuan S, Matemanosak P, Pinjaroen S. Why do pregnant women prefer cesarean delivery?: A qualitative study in a tertiary care center in Southern Thailand. BMC Pregnacy and Childbirth. 2020;1-16.

28. Barros AJD, Victora CG, Horta BL, Wehrmeister FC, Bassani D, Silveira F, et al. Antenatal care and caesarean sections: trends and inequalities in four population-based birth cohorts in Pelotas, Brazil, 1982-2015 (Supplement Article). International Journal of Epidemiology. 2019;i37i45.

29. Oner C, Catak B, Sütlü S, Kilinç S. Effect of social factors on cesarean birth in primiparous women: A cross sectional study (social factors and cesarean birth). Iran J Public Health. 2016;45(6):768-773.

30. Sala A, Lippi G, Franciulli F. Cesarean delivery of low-birth weight infants and its association with maternal variables. Journal of Family Medicine Forecast. 2018;1(1):1003.

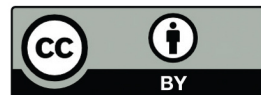

This work is licensed under a Creative Commons Attribution 